\title{
Unapproved Combination Therapy of Doxycycline and Ivermectin in Covid-19 Pandemic, an Opportunistic Chance of Self-medication: A Case Report
}

\author{
Gulnaz Bano ${ }^{1}$, Abhishek Sharma ${ }^{2, *}$ \\ ${ }^{1}$ Department of Pharmacology and Pharmacy Practice, School of Pharmaceutical Education and Research, Jamia Hamdard \\ University, New Delhi, INDIA. \\ ${ }^{2}$ Department of Quality Control and Assurance, Hakeem Abdul Hameed Centenary Hospital and Hamdard Institute of Medical \\ Science and Research, Jamia Hamdard, New Delhi, INDIA.
}

Received: 21 October 2020;

Accepted: 24 December 2020

*Correspondence to:

Dr. Abhishek Sharma,

Department of Quality Control and Assurance, Hakeem Abdul Hameed Centenary Hospital and Hamdard Institute of Medical Science and Research, Jamia Hamdard, New Delhi, INDIA. Email: scientist.abhi12@gmail.com Copyright: (C) the author(s),publisher and licensee Indian Academy of Pharmacists. This is an open-access article distributed under the terms of the Creative Commons Attribution Non-Commercial License, which permits unrestricted non-commercial use, distribution, and reproduction in any medium, provided the original work is properly cited.

\begin{abstract}
To date, no standard drug therapy has proven effective to counter COVID-19 disease. There are only hit and trial based on assumptions and weak evidence that are directing prescribing practices for asymptomatic to symptomatic and serious cases of COVID-19. ICMR being the apex body, responsible for framing the guidelines for the management of disease in India has not yet approved the use of combination doxycycline and ivermectin in the prophylaxis or treatment of Covid-19 cases but being used in the treatment of COVID-19 infection. Their adverse drug reactions individually are well known among scientific community. Doxycycline ADRs range from gastrointestinal, urogenital, neuropsychiatric, respiratory, nervous system to skin and appendages. We have reported a case of doxycycline induced drug allergy (rashes) all over the trunk and legs as a result of self-medication. The event happened after a female patient had complaints of persistent fever and weakness consumed doxycycline and ivermectin on her friend's advice and developed rashes on her trunk and legs. The above ADE is very mild but alarming for the medical fraternity that warrants strict compliance with the electronic/text/online prescription. The usage of doxycycline and ivermectin in the treatment of COVID-19 disease, as an indication of treatment should not be considered prior to any concrete evidence or issuance of treatment, guidelines by the apex body in India.

Key words: COVID-19, Self-medication, ADRs, ADE, ICMR, Doxycycline, Ivermectin, Rashes.
\end{abstract}

\section{INTRODUCTION}

Wuhan virus COVID-19 was declared as an international pandemic by WHO in March 2020. ${ }^{[1]}$ Since then there is a long race for re-purporting of available drugs for newer indications in the treatment of COVID-19. ${ }^{[2]}$ After the initiation of research bodies, provocation from political leaders with extraordinary claims on television media, and fewer unorganized published studies, combination drug therapy prescribing have trended among physicians and clinicians. Due to social or television media making exaggerated statements, comments by political and business personas trigger factor, a newer trend of self-medication during this pandemic has emerged..$^{[3]}$ Although, the strategy of self-medication offers to reduce the burden of healthcare cost reduce time to avail treatment but poses a greater risk of drug resistances, adverse drug events (ADEs) and incorrect diagnosis. ${ }^{[4]}$ According to WHO drug information on general policy issues, self-medication is a way by which an individual can treat his symptoms, ailments which do not require medical consultation. ${ }^{[5]}$ Hence the events of self-medication arises from repeating the previously prescribed medications to purchasing non-prescription drugs. ${ }^{[6]}$ The adverse drug reactions (ADRs) are very common drug-related problems, prevailing in healthcare settings. The monitoring and reporting system of ADRs is being established in hospitals where many healthcare professionals take care of one patient. ${ }^{[7]}$ On the contrary, reporting and management of drug-related problems are questionable in the case of using one's prescription to take for your prophylaxis of COVID-19. The global race for particular drug consumption such as doxycycline and ivermectin would lead to their shortage translating into more production under limited infrastructure and fixed operational efficiency of manufacturing units, leading to substandard quality products flooding the market. Tetracycline, at large is imported to India too. We have an example of the heparin scandal of the United States that happened in 2007, where API imported by China was contaminated, which led to 81 deaths in the US and many cases of allergic reactions. ${ }^{[8]}$

\section{CASE REPORT}

A 23-year-old female with weight $54 \mathrm{Kg}$, height: $5 \mathrm{Ft} 2$ inches presented with her complaints of rashes all over her trunk and legs, in a private clinic on $25^{\text {th }}$ September 2020.

History of presenting illness: The patient consulted her friend for her complaint of persistent fever grade $101-102^{\circ} \mathrm{F}$ since last 2 days, whitish tongue, restlessness and dizziness. The friend forwarded her a WhatsApp message of the treatment prescribed to him by a doctor.

On Examination on $25^{\text {th }}$ September 2020: Vitals were checked and found B.P- $126 / 83 \mathrm{~mm}$ of $\mathrm{Hg}$, pulse- $72 / \mathrm{min}$, AEBE clear, and vitals stable. Family history was not significant. There was no travel history.

Medication History: The patient took the prescribed treatment of her friend with suspicion of COVID-19 positive status. On further inquiry regarding 


\section{Bano and Sharma.: Combination Therapy: A Chance of Self-Medication in the Covid-19 Pandemic}

the test report for rapid antigen or RT-PCR, the patient briefed that no test was conducted. The self-medication treatment was:

1. Tab Doxycycline $100 \mathrm{mg}$ two tablets once a day on the first day, then 100 $\mathrm{mg}$ one tablet twice a day for the next four subsequent days.

2. Tab Ivermectin $12 \mathrm{mg}$ one tablet at night for three days.

3. Tab Vitamin C $500 \mathrm{mg}$ one tablet twice a day for 7 days.

4. Tab Zinc acetate $50 \mathrm{mg}$ one tablet once a day for 7 days.

5. Tab Paracetamol $650 \mathrm{mg}$ one tablet stat on the first day then one tablet twice a day for the next 4 days.

The patient took the whole regime as prescribed from $19^{\text {th }}$ September 2020, till $24^{\text {th }}$ September 2020 when on $25^{\text {th }}$ September, evening at 7:00 P.M. patient experienced rashes over trunk and legs. The patient was prescribed tablet fexofenadine $120 \mathrm{mg}$ and one-shot injection hydrocortisone $500 \mathrm{mg}$ IV bolus. The rashes got subsided within 5 minutes.

\section{Causality Assessment}

Naranjo scale ${ }^{[9]}$ for causality assessment was used to evaluate the above case for a suspected adverse drug reaction. The case was subjected to the 10 questionnaires of the Naranjo scale. The total score was calculated to be 6 which is in the range of 5 to 8 implicating that it is Probable ADR of doxycycline.

\section{DISCUSSION}

In a country like India, prescription drugs are dispensed over the counter (OTC). The study conducted in the Sarjapur area, Bangalore East, investigated that within 10 days, 216 patients took medicines from a local pharmacy without prescription out of which $26.8 \%$ were OTCs drugs, $15.2 \%$ were anti-histaminic, $10 \%$ were antibiotics, $7.8 \%$ were anti-pyretic. The results reported that $55.09 \%$ of drugs dispensed belonged to the Schedule $\mathrm{H}$ category. ${ }^{[10]}$ A cross-sectional online survey conducted from of April 2020 to May 2020 in the city of Dhaka, Bangladesh reveals that out of total ( $\mathrm{N}=626)$ only $28.59 \%$ took the mediations on doctors' advice, remaining $(\mathrm{N}=447) 71.40 \%$ respondents took the medication as "self-medication" through other sources. It is alarming to note that, $(\mathrm{N}=355) 85.33 \%$ of patients out of a total, took medications without getting the test done for COVID-19. ${ }^{[1]}$ In the current, new normal situation, where no appropriate regimen available to counter the Severe Acute Respiratory Syndrome Coronavirus 2 (SARS-CoV-2), the combination therapy of doxycycline and ivermectin is paving its way as a new treatment regime. ${ }^{[12]}$ However, a systematic review of 130 doxycycline associated case reports, published between 1966 and 2003 reports 0.9 to 2 cases of rashes in the regime of 200 $\mathrm{mg}$ on day one, then $100 \mathrm{mg}$ for 6 to 13 days and one case with a dose of $100 \mathrm{mg}$ twice a day for 7 days. ${ }^{[13]}$ Out of total ADEs reported, cases with rashes were less than 1 percent in 130 patients $(\mathrm{N}=130)$, that too from NonUnited states region. ${ }^{[13]}$

With the emergence of the second drug in a combination regimen, ivermectin against the SARS-CoV-2 virus, its safety profile should be considered in a population with hyper-inflammatory conditions. ${ }^{[14]} \mathrm{A}$ systematic review and meta-analysis reports that more clinical trials are needed to evaluate the safety profile of ivermectin in pregnant females and children less than $15 \mathrm{~kg}$ body weight. ${ }^{[14]}$ The commentary on ivermectin integrated mass drug administration provokes the need for more research on how to minimize the rare but severe adverse events (SAEs) such as coma and stupor. ${ }^{[15]}$ A study also highlighted ivermectin as a potential for neurotoxicity in the mammalian central nervous system. ${ }^{[16]}$ As evidenced the drug has the potential to cause harm in patients with hyper-inflammatory status, causing increased permeability of the bloodbrain barrier. ${ }^{[17]}$ Since doxycycline and ivermectin do not interact with each other so no pharmacokinetic alteration is evidenced. In view of the dim light of evidence, the safety profile of this combination therapy should be considered in clinical trials to evaluate re-purposive use in symptoms relief, viral clearance, requirements of oxygen and drug adverse effects. ${ }^{[18]}$ Although, the drug interaction of zinc and tetracycline is of less clinical importance when prescribed together, but commonly associated risks of ADRs such as abdominal cramping, nausea, vomiting, diarrhea is reported above tolerable dose limit. ${ }^{[19]}$ Prolonged use of Zinc may cause lower HDL levels, copper deficiency deficiency, and precipitate hypochromic microcytic anemia. ${ }^{[2]}$ Taking lessons from past on use of drugs since COVID-19 outbreak is of utmost importance. It is a well-understood fact that the demand and supply concept exist in the covid-19 scenario, since it has now a list of documented reports which United States of America had witnessed on the shortage of Hydroxychloroquine leading to its unavailability for the drug of choice treatment of patients with SLE and rheumatism. ${ }^{[21]}$

\section{CONCLUSION}

Self-medication is a global concern in developing countries such as India and Bangladesh. After the introduction of telemedicine guidelines in March, 2020 the Government of India has made it mandatory to abide by rules of telemedicine, but its implementation is very weak. In view of the above case report and past learning experience from hydroxychloroquine global shortage, we recommend:

- The government should restrict the sale of doxycycline and ivermectin in common pharmacies and dispensaries. However, it should only be dispensed against the registered medical practitioner's prescription with proper Medical Council of India (MCI) registered number and signature.

- Every pharmacist should make a separate record of these drug sales by retaining their prescriber's details with the dispensing drug store.

- Strict ban on media programs that violates ethical discussion or allow any leader of a political party, industrialists to discuss the use of particular drugs or combination of drugs and limits the television media to discussion with clinicians and other health care professionals.

- Circulate a red alert notice or advisory on the usage of doxycycline and ivermectin till any clinical practice guidelines come from the apex bodies.

- Indian Pharmacopoeia Commission-Pharmacovigilance Program of India (PvPI) should increase its adverse drug monitoring centers in India, while the Health Ministry should ensure that there shall be at least one dedicated clinical pharmacist on every 100 beds working in every government hospitals of India, who can promote the judicious use of drugs inside the hospital.

\section{CONFLICT OF INTEREST}

The authors declare no conflict of interest.

\section{ABBREVIATIONS}

ADR: Adverse drug reaction; ADE: Adverse Drug Event; ICMR: Indian council of Medical Research; API: Active pharmaceutical ingredient; BP: Blood pressure; AEBE: Air entry bilaterally equal; HDL: High density lipoprotein. 


\section{REFERENCES}

1. WHO Director-General's opening remarks at the media briefing on COVID-19-11 March 2020. Available at https://www.who.int/director-general/speeches/detail/ who-director-general-s-opening-remarks-at-the-media-briefing-on-covid-19-11-march-2020 [Accessed October 20, 2020]

2. Kandeel M, Al-Nazawi M. Virtual screening and repurposing of FDA approved drugs against COVID-19 main protease. Life Sci. 2020;251:117627.

3. Mallhi TH, Khan $\mathrm{YH}$, Alotaibi NH, et al. Drug repurposing for COVID-19: a potential threat of self-medication and controlling measures [published online ahead of print, 2020 Aug 26]. Postgrad Med J. 2020;postgradmedj-2020-138447.

4. Eticha T, Mesfin K. Self-medication practices in Mekelle, Ethiopia. PLoS One. 2014;9(5):e97 464.

5. WHO Drug Information Vol. 14, No. 1, 2000. Available at: http://digicollection.org/ hss/en/d/Jh1462e/ [Accessed October 20, 2020]

6. Malik M, Tahir MJ, Jabbar R, Ahmed A, Hussain R. Self-medication during Covid-19 pandemic: challenges and opportunities [published online ahead of print, 2020 Oct 3]. Drugs Ther Perspect. 2020;1-3.

7. Sriram S, Ghasemi A, Ramasamy R, et al. Prevalence of Adverse Drug Reactions at a Private Tertiary Care Hospital in South India. J Res Med Sci. 2011;16(1):16-25.

8. Gagnon MA. Drug shortages: Searching for a cure. Healthc Policy. 2012;7(4):10-7.

9. Naranjo CA, Busto U, Sellers EM, Sandor P, Ruiz I, Roberts EA, Janecek E, Domecq C, Greenblatt DJ. A method for estimating the probability of adverse drug reactions. Clin Pharmacol Ther. 1981 Aug;30(2):239-45.

10. Nagaraj M, Chakraborty A, Srinivas BN. A Study on the Dispensing Pattern of Over the Counter Drugs in Retail Pharmacies in Sarjapur Area, East Bangalore. J Clin Diagn Res. 2015;9(6):Fc11-3.

11. Nasir M, Salauddin CAS, Zahan T. Self-medication during COVID-19 outbreak:
A cross sectional online survey in Dhaka city. Int J Basic Clin Pharmacol. 2020;9(9):1325-30.

12. Sen GPS, Rana MK. Ivermectin, Famotidine and Doxycycline: A Suggested Combinatorial Therapeutic for the Treatment of COVID-19. ACS Pharmacol TransI Sci. 2020;3(5):1037-8.

13. Smith K, Leyden JJ. Safety of doxycycline and minocycline: a systematic review. Clin Ther. 2005;27(9):p.1329-42.

14. Navarro M, Camprubí D, Requena-Méndez A, Buonfrate D, Giorli G, Kamgno J, et al. Safety of high-dose ivermectin: A systematic review and meta-analysis. J Antimic Chemoth. 2020;75(4):827-34.

15. Richards FO, Jr. Upon entering an age of global ivermectin-based integrated mass drug administration for neglected tropical diseases and malaria. Malar $\mathrm{J}$, 2017;16(1):p.168.

16. Menez C, Sutra JF, Prichard R, Lespine A. Relative neurotoxicity of ivermectin and moxidectin in Mdr1ab (-/-) mice and effects on mammalian GABA (A) channel activity. PLoS Negl Trop Dis. 2012;6(11):e1883.

17. Chaccour C, et al. Ivermectin and COVID-19: Keeping Rigor in Times of Urgency. Am J Trop Med Hyg. 2020;102(6):p.1156-7.

18. Molento MB. COVID-19 and the rush for self-medication and self-dosing with ivermectin: A word of caution. One Health. 2020;10:100148.

19. Penttilä $\mathrm{O}$, Hurme $\mathrm{H}$, Neuvonen PJ. Effect of zinc sulphate on the absorption of tetracycline and doxycycline in man. Eur J Clin Pharmacol, 1975. 9(2-3): p.131-4.

20. Saper RB, Rash R. Zinc: An essential micronutrient. Am Fam Physician. 2009;79(9):768-72.

21. Peschken CA. Possible Consequences of a Shortage of Hydroxychloroquine for Patients with Systemic Lupus Erythematosus amid the COVID-19 Pandemic. J Rheumatol. 2020;47(6):787-90.

Cite this article as: Bano G, Sharma A. Unapproved Combination Therapy of Doxycycline and Ivermectin in Covid-19 Pandemic, an Opportunistic Chance of Self-medication: A Case Report. J Pharm Pract Community Med. 2020;6(4):69-71. 